\title{
BMJ The net effect of smoking on healthcare Open and welfare costs. A cohort study
}

\author{
Jari Tiihonen, ${ }^{1-3}$ Kimmo Ronkainen, ${ }^{4}$ Aki Kangasharju, ${ }^{5}$ Jussi Kauhanen ${ }^{4}$
}

To cite: Tiihonen J, Ronkainen K, Kangasharju A, et al. The net effect of smoking on healthcare and welfare costs. A cohort study. BMJ Open 2012;2:e001678. doi:10.1136/bmjopen-2012001678

- Prepublication history and additional material for this paper are available online. To view these files please visit the journal online (http://dx.doi.org/10.1136/ bmjopen-2012-001678)

Received 20 June 2012 Revised 14 November 2012 Accepted 14 November 2012

This final article is available for use under the terms of the Creative Commons Attribution Non-Commercial 2.0 Licence; see http://bmjopen.bmj.com

\footnotetext{
${ }^{1}$ Department of Clinical Neuroscience, Karolinska Institutet, Stockholm, Sweden

${ }^{2}$ National Institute for Health and Welfare, Helsinki, Finland ${ }^{3}$ Departments of Psychiatry and Forensic Psychiatry, University of Eastern Finland, Niuvanniemi Hospital and Kuopio University Hospital, Kuopio, Finland

${ }^{4}$ Institute of Public Health and Clinical Nutrition, University of Eastern Finland, Kuopio, Finland

${ }^{5}$ Government Institute for Economic Research, Helsinki, Finland
}

\section{Correspondence to}

Dr Jari Tiihonen; jari.tiihonen@niuva.fi or jari.tiihonen@ki.se

\section{ABSTRACT}

Objective: To study the net economic effect of smoking on society.

Design: Prospective cohort study.

Setting: Eastern Finland.

Patients: We studied mortality, paid income and tobacco taxes, and the cumulative costs due to pensions and medical care among tobacco smoking and non-smoking individuals in a 27-year prospective cohort study of 1976 men from Eastern Finland. These individuals were 54-60 years old at the beginning of the follow-up.

Main outcome measures: The net contribution of smoking versus non-smoking individuals to public finance balance (euros).

Results: Smoking was associated with a greater mean annual healthcare cost of $€ 1600$ per living individual during follow-up. However, due to a shorter lifespan of 8.6 years, smokers' mean total healthcare costs during the entire study period were actually $€ 4700$ lower than for non-smokers. For the same reason, each smoker missed 7.3 years ( $€ 126850)$ of pension. Overall, smokers' average net contribution to the public finance balance was $€ 133800$ greater per individual compared with non-smokers. However, if each lost quality adjusted life year is considered to be worth $€ 22200$, the net effect is reversed to be $€ 70200$ ( $€ 71.600$ when adjusted with propensity score) per individual in favour of non-smoking.

Conclusions: Smoking was associated with a moderate decrease in healthcare costs, and a marked decrease in pension costs due to increased mortality. However, when a monetary value for life years lost was taken into account, the beneficial net effect of nonsmoking to society was about $€ 70000$ per individual.

\section{INTRODUCTION}

Smoking is the single most important preventable cause of premature death in industrialised countries, ${ }^{1}$ and tobacco taxation is still the most cost-effective method for decreasing the prevalence of smoking. Increases in tobacco taxes have encouraged $9-17 \%$ of smokers to quite, ${ }^{23}$ and in the long run the main effect of taxation is a reduction in the incidence of new young smokers. ${ }^{4}$ Early smoking cessation increases lifespan by about $9-10$ years, ${ }^{5}$ and if the smoking rate diminished by 10 percentage

\section{ARTICLE SUMMARY}

Article focus

- No results have been obtained from prospective individual level data based on mortality, morbidity, pension and healthcare costs and, therefore, the net economic impact of smoking on society has remained unclear.

Key messages

- Healthcare and pension costs are lower for smokers than non-smokers, the overall difference being more than 100000 euros per individual.

- However, when a monetary value for life years lost was taken into account, the beneficial net effect of non-smoking to society was about $€ 70000$ per individual.

Strengths and limitations of this study

- This study provides the first evidence of the net economic effect of smoking versus non-smoking on costs related to health and social welfare, based on prospective data from individual subjects.

- Only men were included in the study.

points, life expectancy would increase by about 1 year. It has been estimated that a $10 \%$ increase in the price of smoked tobacco will result in about a 5\% decrease in cigarette consumption, ${ }^{4}$ yet tobacco taxes are still low in many countries. Thus, it would be interesting to know why so many governments in the world continue to increase spending on healthcare costs, while a substantial savings and advances in life expectancy are readably available by administratively increasing tobacco taxes. There are two plausible explanations: the governments do not know about the correlation between increasing tobacco taxes on increasing life expectancy, or they realise this effect, but do not want to increase life expectancy. One possible explanation is that governments are reacting to pressure from cigarette companies and smokers (either implicit or explicit) which prevents tax increases.

The net effect of smoking on healthcare costs has been investigated in several studies. ${ }^{6-18}$ Some modelling studies have suggested that although smokers suffer more 
from many kinds of diseases, non-smokers incur more healthcare costs because they live longer, ${ }^{6-8} \quad 11 \quad 12$ yet others have reached the opposite conclusion. ${ }^{9} \quad 10 \quad 13-18$ Only a few of these studies have included pension and insurance costs, ${ }^{7} 12 \quad 17 \quad 18$ and paid tobacco taxes. ${ }^{12} 17 \quad 18$ In 2001, Philip Morris provided a report to the Government of the Czech Republic, which indicated that the effect of smoking on the public finance balance in the Czech Republic in 1999 was positive and estimated to be 5815 million korunas (about 150 million USD). ${ }^{12}$ Although this report generated outraged reactions worldwide, Milos Zeman, the Czech prime minister stated:

As a smoker, I support the state budget, because in the Czech Republic, we pay tax on tobacco. Also, smokers die sooner, and the state does not need to look after them in their old age. ${ }^{19} 20$

This report was based on many assumptions that were obtained through theoretical modelling, and it did not give any monetary value for life years lost because of smoking, and it was claimed to have underestimated the costs of medical care for people suffering from smoking related diseases. $^{21}$ The overall net effect of smoking on private (personal) and external costs has also been studied by Sloan et $a l^{17}$ and Viscusi, ${ }^{18}$ who used US lifetable data to model the forthcoming lifelong net costs caused by smoking. As shown by van Baal et al, ${ }^{22}$ slightly different models can give markedly different results on the net effect of smoking, depending on what assumptions are used. In any case, sophisticated incidencebased datasets are ultimately required to establish the true healthcare costs incurred by smoking. ${ }^{23}$ Since no results have been obtained from prospective, individual level data based on mortality, morbidity, pension and healthcare costs, the net economic impact of smoking on society has remained unclear. The aim of this study was to investigate this net economic effect by using data from a prospective 27-year follow-up of a cohort of 1976 Finnish middle-aged men.

\section{METHODS}

Study population

The subjects of the Kuopio Ischemic Heart Disease study (KIHD) were obtained from a randomly selected sample of 3433 men, aged 42 to 60 years, who resided in the town of Kuopio or its surrounding rural communities. Of those invited, $2682(83 \%)$ participated in the study. Of these, individuals from 54 to 60 years with complete data for smoking, income, healthcare costs, retirement and mortality ( $n=1976$ men) were included in the final analyses. The baseline examinations were conducted between March 1984 and December 1989. ${ }^{24}$ The mean follow-up time was 24.2 years (range $21.1 \pm 26.8$ years). The KIHD study was approved by the Research Ethics Committee of the University of Kuopio, in Kuopio,
Finland. Each participant gave written informed consent. The end of the follow-up period was 31 December 2010.

A subject was defined as a smoker if he had ever smoked on a regular basis, and had smoked cigarettes, cigars or a pipe within the past 30 days. The lifelong exposure to smoking ('cigarette pack-years') was estimated as the product of years smoked and the number of tobacco products smoked daily at the time of examination. 'Years smoked' were defined as the sum of years of smoking regardless of when smoking had started, whether the subject had stopped smoking, or whether it had occurred continuously or during several periods. Data on mortality were obtained from Statistics Finland, and data on healthcare costs from the Finnish Institute for Health and Welfare (THL). The healthcare costs did not include visits to general practitioners, home nursing, or medication and dental care costs in outpatient care, which have been estimated to be about $20-30 \%$ of total healthcare costs in this age group in Finland. ${ }^{25}$ The amount of paid tobacco taxes was estimated on the basis of cigarette pack-years, ${ }^{26}$ and the amount of paid income taxes was estimated by using the income tax rate for the year 1987. The amount of occupational productivity and income taxes lost was calculated as the difference of age at retirement (relative to the retirement age of matched non-smokers) multiplied by the annual income and income tax of each smoker. 'Income taxes paid' also included obligatory pension and healthcare insurance fees. All monetary values were expressed as Euros $(€)$ and converted to the level for the year 2009.

In the UK, the monetary value of one quality adjusted life year (QALY) has been estimated to be 20 000-30 000 Pounds for an individual having perfect health. ${ }^{27}$ In the present study, we used a value of 30000 Euros (about 25100 Pounds in February 2012). In a recent large study on the effect of smoking on life expectancy, the quality-of-life score among former smokers with a body mass index (BMI) of 25-30, who were older than 65-years was estimated to be $0.71-0.77 .^{28}$ Therefore, we used a quality-of-life score of 0.74 for smokers in the present study, thus equalling to $0.74 \times 30000$ Euros=22 200 Euros for each life year lost due to smoking among former smokers aged over 65 years (deceased smokers who would be over 65 if they had lived).

\section{Statistical analysis}

Differences in baseline characteristics and costs were examined using the Student's t-test. Descriptive data are presented as means and percentages. A p value of less than 0.05 was considered statistically significant. These statistical analyses were performed using SPSS 17.0 for Windows. Life expectancy for those individuals still alive on 31st December 2009 was calculated by using life expectancy from the Life Table provided by Statistics Finland. ${ }^{29}$

Adjusted group difference in total cost was also assessed using bootstrap type analysis of covariance (ANCOVA) with adjustments for the propensity score. 
Potential variables for inclusion in the propensity score (age at baseline, BMI, systolic blood pressure, low-density lipoprotein (LDL)-cholesterol and years of education) were explored in logistic regression with a backward selection procedure $(\mathrm{p}<0.25$ as selection criterion). Patients were stratified based on quintiles of the propensity score. Furthermore, the fit of the propensity score model was assessed by the Hosmer-Lemeshow test.

\section{RESULTS}

The crude mortality rates were $351 / 493$ (71.2\%) among smokers, and 553/1483 (37.3\%) among non-smokers, and the cause-specific mortality in each group is shown in table 1 . The observed age at death was 67.8 years for smokers, and 71.4 years for non-smokers. The predicted mean age at death was 72.1 for smokers and 80.7 years for non-smokers, indicating 8.6 years difference between two groups. When the effect of birth year on life expectancy was taken into account, the amount of life years lost due to smoking was 9.2 years. The demographic variables and smoking-related outcomes are shown in table 2. Smokers had substantially lower mean BMI and educational level. Smokers also had a slightly lower mean systolic blood pressure and a slightly higher mean LDL cholesterol level. Smoking was associated with a moderate decrease in productive occupational career, income taxes paid and hospital care costs, and showed a marked decrease in pension costs. The net effect of smoking on public finance was plus $€ 133800$ for these smokers during the follow-up when life years lost were not included, and minus $€ 70200$ when a monetary value for life years lost was included in the calculation. When the propensity score method was applied, the result remained almost the same $(€ 71.600,95 \%$ CI $€ 52.300$ to $€ 90.800)$.

Figure 1 demonstrates the average annual healthcare costs as a function of age among those individuals still alive, and figure 2 shows the corresponding results when all individuals (also deceased) are included. The higher

\begin{tabular}{l}
$\begin{array}{l}\text { Table } 1 \text { Cause-specific } \\
\text { non-smokertality among smokers and }\end{array}$ \\
\hline \begin{tabular}{lll} 
Cause of death & $\begin{array}{l}\text { Non-smokers } \\
(\%)\end{array}$ & $\begin{array}{l}\text { Smokers } \\
(\%)\end{array}$ \\
\hline Cardiovascular disease & $267(48 \%)$ & $166(47 \%)$ \\
Cancer (all) & $146(26 \%)$ & $102(29 \%)$ \\
Lung cancer & $15(3 \%)$ & $47(13 \%)$ \\
Respiratory disease & $13(2 \%)$ & $20(6 \%)$ \\
External causes of & $56(10 \%)$ & $28(8 \%)$ \\
death & $71(13 \%)$ & $35(10 \%)$ \\
Other & $553(100 \%)$ & $351(100 \%)$ \\
\hline Total
\end{tabular}
\end{tabular}

A total of $553(37.3 \%)$ non-smokers and $351(71.2 \%)$ smokers had died during the follow-up. Percentages indicate the proportions for cause of death from all deaths in each group. Cancer deaths include lung cancer deaths. mortality results in lower annual cost among smokers after 72 years from birth.

\section{DISCUSSION}

Hospital care costs were 1600 Euros greater per person year for living individuals among smokers during the follow-up, but due to a 8.6 year shorter lifespan, the total costs per individual were 4700 Euros lower among smokers than non-smokers during the entire study period. This study provides the first evidence of the net economic effect of smoking versus non-smoking on costs related to health and social welfare, based on prospective, individual level data.

Smoking resulted in a moderate decrease in the productive occupational career and income taxes and pension fees paid, a moderate decrease in healthcare costs and a marked decrease in the pension costs. The costs of smoking to society have been modelled by using estimates on increased mortality and morbidity. ${ }^{6-18}$ However, none of these modelling studies investigated the overall net economic effect of smoking on public finance balance by using actual data from individuals, and only a few had taken into account all the following factors; lifetime productivity or income taxes and pension fees paid, pension costs, and a monetary value of life years lost. ${ }^{17} 18$ Our results indicate that combined, these factors make a considerable contribution to the overall net effect than merely healthcare costs which is in line with the modelling studies by Sloan et $a l^{17}$ and Viscosi. ${ }^{18}$ If the potential increase in quality adjusted life years is taken into account, our results suggest that the life long net beneficial economic effect of early smoking cessation is more than $€ 70000$ per individual, and this sum did not change substantially when propensity score was applied in the analysis. Our results also indicate that reducing the rate of smoking has a huge beneficial economic effect on society, mainly due to increased lifespan and continued pension costs. In Finland, the National Institute for Health and Welfare aims to make Finland free of smoking by the year 2040. Since there are currently about 900000 smokers in Finland, the average net effect of $€ 134000$ per individual on public finance balance (without taking into account the monetary value of life years lost) would correspond during the next decades to about 120 billion Euros total increase in costs (over 2.5-fold to annual state budget). However, this nominal deficit would be massively outweighed by about 2 years increase in life expectancy of the whole nation.

Our overall results on the net economic effect of smoking on public finance balance are contrary to the Philip Morris report. A major reason for this difference is that Little did not consider the inherent value of the quality adjusted life years lost. In other words, if we used an estimate of 0 Euros for each lost year of human life, then the positive economic effect of smoking in our study would have been even larger than the effect 
Table 2 Smoking-related outcomes

\begin{tabular}{|c|c|c|c|c|c|c|}
\hline & \multicolumn{2}{|c|}{$\begin{array}{l}\text { Non-smokers } \\
\mathrm{N}=1483\end{array}$} & \multicolumn{2}{|c|}{ Smokers $N=493$} & \multirow[b]{2}{*}{$\begin{array}{l}\text { Difference } \\
\text { of means }\end{array}$} & \multirow[b]{2}{*}{$p$ Value } \\
\hline & Mean & SD & Mean & SD & & \\
\hline Age at baseline, years & 55.72 & 2.50 & 55.54 & 2.38 & -0.2 & 0.17 \\
\hline Body mass index (BMI) & 27.29 & 3.51 & 26.01 & 3.81 & -1.3 & $<0.001$ \\
\hline Mean systolic blood pressure $(\mathrm{mm} \mathrm{Hg})$ & 135.93 & 17.43 & 133.43 & 18.18 & -2.5 & 0.007 \\
\hline LDL-cholesterol (mmol/l) & 4.07 & 1.01 & 4.21 & 1.09 & 0.1 & 0.013 \\
\hline Years of education & 8.19 & 3.32 & 7.52 & 2.74 & -0.7 & $<0.001$ \\
\hline Age at death, years & 80.71 & 8.40 & 72.13 & 8.89 & -8.6 & $<0.001$ \\
\hline Life years lost due to smoking & 0 & 0 & 9.19 & 8.15 & 9,2 & $<0.001$ \\
\hline Age at retirement, years & 56.60 & 5.89 & 55.35 & 6.23 & -1.3 & $<0.001$ \\
\hline Years of receiving pension & 23.69 & 9.11 & 16.42 & 9.39 & -7.3 & $<0.001$ \\
\hline Number of hospitalisations & 10.74 & 12.34 & 10.84 & 10.89 & 0.1 & 0.88 \\
\hline Number of inpatient days & 88.47 & 235.25 & 101.55 & 216.23 & 13.1 & 0.28 \\
\hline Years of smoking (at baseline) & 2.69 & 8.96 & 31.81 & 9.72 & 29.1 & $<0.001$ \\
\hline Annual income, $€$ & 34060 & 22180 & 27510 & 17.730 & -6550 & $<0.001$ \\
\hline Occupational productivity lost due to smoking, $€$ & 0 & 0 & 34370 & 27080 & 34370 & $<0.001$ \\
\hline Income taxes lost due to smoking, $€$ & 0 & 0 & 11660 & 12550 & 11660 & $<0.001$ \\
\hline Annual pension, $€$ & 20440 & 13330 & 16180 & 9730 & -4260 & $<0.001$ \\
\hline Reduced pension costs due to smoking, $€$ & 0 & 0 & 126850 & 148120 & 126850 & $<0.001$ \\
\hline Reduced income taxes paid from pensions, $€$ & 0 & 0 & 34230 & 48650 & 34230 & $<0.001$ \\
\hline Annual healthcare costs/living individuals, $€$ & 3420 & 9870 & 5040 & 10650 & 1620 & 0.003 \\
\hline Total healthcare costs, $€$ & 79290 & 173420 & 74570 & 154950 & -4720 & 0.59 \\
\hline Tobacco tax paid, $€$ & 2190 & 8860 & 50300 & 32450 & 48110 & $<0.001$ \\
\hline Life years lost due to smoking, $€$ & 0 & 0 & 203960 & 180890 & 203960 & $<0.001$ \\
\hline Total costs, life years lost not included, $€$ & 77110 & 173840 & -56680 & 195130 & -133790 & $<0.001$ \\
\hline Total costs, life years lost included, $€$ & 77110 & 173840 & 147280 & 195960 & 70170 & $<0.001$ \\
\hline \multicolumn{7}{|c|}{$\begin{array}{l}\text { Total costs of smoking versus non-smoking were calculated by taking into account the life-long difference ( } € \text { /person) of healthcare costs } \\
\text { ( } € 4720) \text {, tobacco taxes paid }(€ 48110) \text {, income taxes lost }(€ 11660) \text {, reduced pension costs }(€ 126850) \text { and reduced taxes paid from pensions } \\
(€ 34230) \text {. The smoking-related harms for the society were } € 11660+€ 34230=€ 45890 \text {, and the smoking-related benefits for the society were } \\
€ 4720+€ 48110+€ 126850=€ 179680 \text {, and thus the net effect on public finance balance was } € 133790 \text { positive for each smoking individual. } \\
\text { When the value of } 9.19 \text { life years lost due to smoking ( } € 203960) \text { was taken into account, the net effect became } € 70170 \text { negative for each } \\
\text { smoking individual. 'Income taxes lost due to smoking' indicate the loss due to earlier disability/retirement, and 'Pension costs' indicate the } \\
\text { pensions paid by the state and pension companies. The value of one quality adjusted life year lost was estimated to be } 0.74 \times € 30000= \\
€ 22200^{10}{ }^{25}\end{array}$} \\
\hline
\end{tabular}

estimated by Little. However, when considering the implications of these results, the major question is whether or not humans are to be valued as commodities, like domesticated animals, or does human life

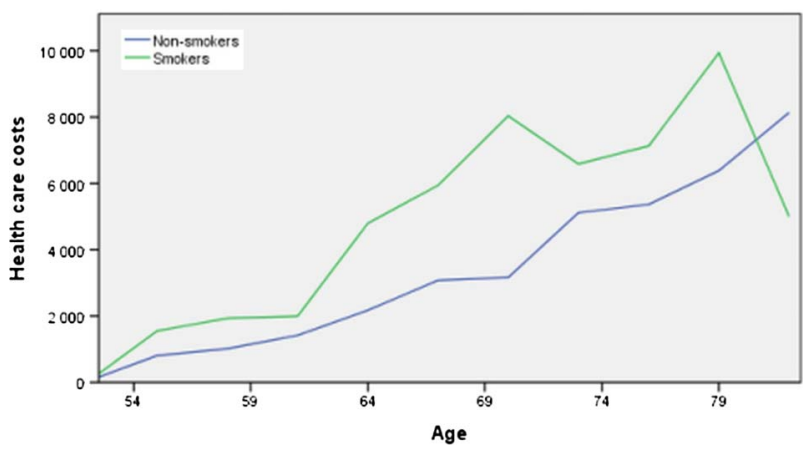

Figure 1 Average annual health care costs per living individual, in Euros, as a function of age. maintain an inherent value even when the individual is no longer economically productive, as in retirement? In the field of healthcare, it is generally assumed that all human life-even that of the old and disabled-is

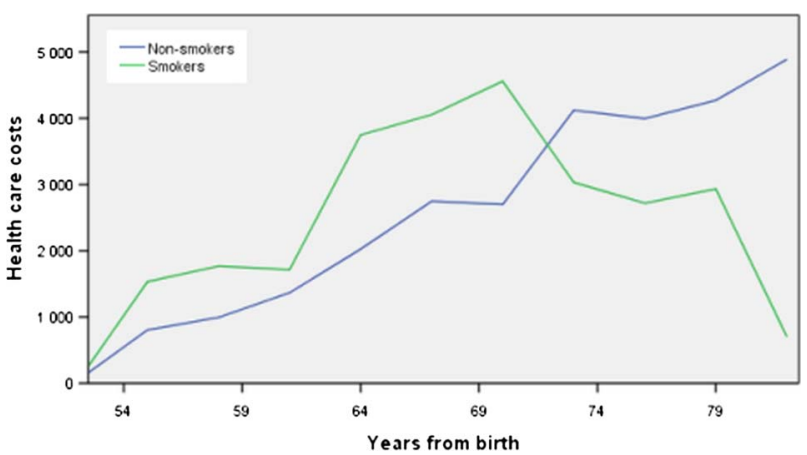

Figure 2 Average annual healthcare costs among all individuals in Euros (including deceased persons). 
precious and has value. This view is also currently accepted by national authorities throughout most of the modern world. Already in 1999, 387 billion USD was used in the US for medical treatment and care of people older than 65 years. ${ }^{30}$ Nowadays, it is generally agreed that the monetary value of one additional life year of a healthy human being is about 20000-30000 British Pounds when additional costs of medical care are considered. ${ }^{27}$ One may ask why societies continue to invest even larger amounts of money and other social resources to achieve a longer mean lifespan for citizens, when a more drastic increase could be achieved administratively, without any further costs, by substantially raising tobacco taxes and otherwise restricting access to smoking? There are two likely answers: either governmental authorities have not realised this fact, or they have realised it, but do not want to increase life expectancy due to a subsequent increase in healthcare and pension costs.

While denying access to medical care for older people, in order to prevent a deficit in the national economy, would not be possible because of common ethical concerns and public opinion, preventing a decrease in smoking rates essentially has the same effect, and is apparently more acceptable to many societies. If this is the case, it would also explain the reluctance of governments to regulate eating and other consumption habits that negatively affect the general population by, for example, increasing the value added tax (VAT) on food products that are high in sugar and saturated fats, and decreasing VAT on fruits and vegetables, for example. The Czech prime minister stated in 2001 that smoking is beneficial for the state, because smokers die sooner. ${ }^{17}{ }^{18}$ Such comments have not been echoed by other state leaders; however, it is possible that this view still influences tobacco policies in many modern countries. Therefore, governments should be transparent concerning which kind of knowledge their tobacco and food taxation policy is based on. Our study cannot answer the question on why cigarette taxes are still low in many countries. Therefore, this remains open and a topic for further research.

The strength of this study is based on empirical data that were gathered from a 27-year prospective study. Thus, no assumptions on healthcare, pension costs or discount percentages of future costs were needed. One shortcoming is that this study did not include women, and it did not include visits to general practitioners, home nursing or medication and dental care costs in outpatient care, which contribute to about $20-30 \%$ of the total healthcare costs among elderly and middle-aged people in Finland.$^{25}$ In a previous 19-year follow-up study, it was observed that although the overall healthcare costs were higher among smokers aged 25-59 years, the costs of medication in outpatient care did not differ between smokers and non-smokers. ${ }^{31}$ Thus, it can be further estimated that the total healthcare costs might have been at the most about 6000 to 7000 Euros higher per individual among non-smokers when compared with smokers, instead of our modest estimate of about 5000 Euros per individual. However, the magnitude of this difference $(€$ $1000-2000$ ) is less than $2 \%$ of the pension costs, and does not have any substantial effect on these results. We also did not include the costs of fires or littering related to smoking, as this information was not available, yet the combined contribution of these factors is probably less than $1 \%$ of the total costs. ${ }^{12}$ Since only $17 \%$ of the initiated subjects refused to participate, the generalisability of the results can be considered quite sufficient.

It was presumed that smokers' lower education level and lower income level were not caused by smoking, and that differences in these characteristics were associated with smoking due to the fact that less educated individuals are more likely to start smoking than individuals with a higher educational level. Therefore, it was assumed that smoking cessation would not substantially increase education level or income. It can be estimated that during a productive career of about 35 years, with an annual difference of $€ 2970$ in paid income taxes, smokers in our study have paid an average of about 100000 Euros less income taxes than non-smokers. If it were assumed that early smoking cessation would change these variables to the same levels as with nonsmokers, the net difference between smokers versus nonsmokers would shift from $€ 134000$ to about $€ 30000$ in favour of smoking, if the value of life years lost are not included, and from $€ 70000$ to about $€ 170000$ in favour of non-smoking if the value of life years lost are included in the analysis. Either way, the principal conclusions on the net costs would remain the same. It is questionable if tobacco taxes should be considered as beneficial increases in income to the state. For example, if an individual would not have been smoking, then he/she probably would have consumed more goods in the extra years of life and thus paid more taxes for those goods instead of the taxes paid for cigarettes. Overall, the estimate of a $€ 70000$ beneficial effect of early smoking cessation per individual is probably an underestimate.

Contributors JT, JK and AK conceived the idea of the study and were responsible for design of the study. KR and JK were responsible for undertaking for data analysis and produced the tables and graphs. JT and AK provided input into data analysis. The initial draft of the manuscript was prepared by JT and then circulated repeatedly among all the authors for critical revision. KR was responsible for acquisition of the data and JT, JK, $\mathrm{KR}$ and $\mathrm{AK}$ contributed to interpretation of the results.

Funding This project was funded by the Ministry of Health and Social Affairs (Finland), the National Institute for Health and Welfare (THL) and the Academy of Finland. The funders were not involved in the conduct of the study, or in the collection, management, analysis or interpretation of the data.

Competing interests All the authors have completed the Unified Competing Interest form at http://www.icmj.org.coi_disclosure.pdf (available on request from the corresponding author) and declare: Dr Tiihonen is a member of the advisory board of AstraZeneca and Janssen-Cilag, and he reports as a consultant to Lundbeck, Organon, Janssen-Cilag, Eli Lilly, AstraZeneca, F. Hoffman-La Roche and Bristol-Myers Squibb. He has received fees for giving expert opinions to Bristol-Myers Squibb and GlaxoSmithKline, and lecture fees from Janssen-Cilag, Bristol Myers-Squibb, Eli Lilly, Pfizer, 
Lundbeck, GlaxoSmithKline, Novartis and Astra Zeneca. No further disclosures were reported.

Ethics approval The KIHD study was approved by the Research Ethics Committee of the University of Kuopio, in Kuopio, Finland.

Provenance and peer review Not commissioned; externally peer reviewed.

Data sharing statement No additional data are available.

\section{REFERENCES}

1. Schroeder SA, Warner KE. Don't forget tobacco. N Engl J Med 2010;363:201-4.

2. Dunlop SM, Cotter TF, Perez DA. Impact of the 2010 tobacco tax increase in Australia on short-term smoking cessation: a continuous tracking survey. Med J Aust 2011;195:469-72.

3. Choi TC, Toomey TL, Chen V, et al. Awareness and reported consequences of a cigarette tax increase among older adolescents and young adults. Am J Health Promot 2011;25:379-86.

4. Gallet CA, List JA. Cigarette demand: a meta-analysis of elasticities. Health Econ 2003;12:821-35.

5. Doll R, Peto R, Boreham J, et al. Mortality in relation to smoking: 50 years' observations on male British doctors. BMJ 2004;328:1519.

6. Leu RE, Schaub T. Does smoking increase medical care expenditure? Soc Sci Med 1983;17:1907-14.

7. Manning WG, Keeler EB, Newhouse JP, et al. The taxes of sin. Do smokers and drinkers pay their way? JAMA 1989;261:1604-9.

8. Lippiatt BC. Measuring medical cost and life expectancy impacts of changes in cigarette sales. Prev Med 1990;19:515-32.

9. MacKenzie TD, Bartecchi CE, Schrier RW. The human costs of tobacco use. N Engl J Med 1994;330:975-80.

10. Health Program, Office of Technology Assessment. Smoking-related deaths and financial costs: estimates for 1990. Rev. ed. Washington, DC: Office of Technology Assessment, 1993.

11. Barendregt JJ, Bonneux L, van der Maas PJ. The health care costs of smoking. N Engl J Med 1997;337:1052-7.

12. Arthur D. Little International, Inc. Philip Morris funded study of smoking in the Czech Republic stating that the Czech government had a net gain of $\$ 147.1$ million from smoking. http://www.mindfully org/Industry/Philip-Morris-Czech-Study.htm (accessed 21 Nov 2011)

13. Yang L, Sung HY, Mao Z, et al. Economic costs attributable to smoking in China: update and an 8-year comparison, 2000-2008. Tob Control 2011;20:266-72.
14. Callum C, Boyle S, Sandford A. Estimating the cost of smoking to the NHS in England and the impact of declining prevalence. Health Econ Policy Law 2011;6:489-508.

15. Miller VP, Ernst C, Collin F. Smoking-attributable medical care costs in the USA. Soc Sci Med 1999;48:375-91.

16. Miller LS, Max W, Sung HY, et al. Evaluation of the economic impact of California's Tobacco Control Program: a dynamic model approach. Tob Control 2010;19(Suppl 1):i68-76.

17. Sloan FA, Ostermann J, Picone G Jr, et al. The price of smoking. Cambridge, Massachusetts, London, England: The MIT Press, 2004.

18. Viscusi WK. The governmental composition of the insurance costs of smoking. J Law Econom 1999;42:574-609.

19. L'Organisation mondiale de la Santé. Guide pour la mise en place de l'action antitabac. 2006:21.

20. Holley D. (5 August 2001): "Philip Morris Angers Czechs With Tobacco Toll Report-Los Angeles Times" . Los Angeles Times. http://articles.latimes.com/2001/aug/05/news/mn-30831 (accessed 12 Dec 2011)

21. htt://www.tobacco.org/news/70612.html (accessed 23 Dec 2011)

22. van Baal PH, Feenstra TL, Polder JJ, et al. Economic evaluation and the postponement of health care costs. Health Econ 2011;20:432-45.

23. Heaney D. The health care costs of smoking. N Engl J Med 1998;338:471; author reply 472.

24. Lakka TA, Venäläinen JM, Rauramaa $R$, et al. Relation of leisure-time physical activity and cardiorespiratory fitness to the risk of acute myocardial infarction in men. N Engl J Med 1994;330:1549-54.

25. Kuntaliitto. Suurten kaupunkien terveydenhuollon kustannukset vuonna 2010. Helsinki: Suomen kuntaliitto, 2011.

26. Official Statistics of Finland. Tobacco Statistics 2009. Helsinki: Statistics Finland, 2010.

27. National Institute for Health and Clinical Excellence. Measuring effectiveness and cost effectiveness: the QALY. http://www.nice.org.uk/ newsroom/features/measuringeffectivenessandcosteffectivenesstheqaly. jsp (accessed 12 Dec 2011).

28. Stewart ST, Cutler DM, Rosen AB. Forecasting the effects of obesity and smoking on U.S. life expectancy. N Engl J Med 2009;361:2252-60.

29. Statistics Finland. Life Table 2007/Life expectancy of men, by age. Statistics Finland. http://www.staft.fi/til/kuol/tau.html (accessed 9 Feb 2012).

30. Keehan SP, Lazenby HC, Zezza MA, et al. Age estimates in the national health accounts. Health Care Financing Rev 2004;1:1-16.

31. Kiiskinen U, Vartiainen E, Puska P, et al. Smoking-related costs among 25 to 59 year-old males in a 19-year individual follow-up. Eur J Publ Health 2002;12:145-51. 